\title{
Nanoheating without Artificial Nanoparticles
}

\section{Vincze Gy' ${ }^{1}$, Szigeti $\mathbf{G y}^{2}$, Andócs $\mathbf{G}^{3}$ and Szász $A^{1}$}

${ }^{1}$ Department of Biotechnics, St. Stephen University, 2100-Gödöllö, Páter K. u. 1., Hungary

${ }^{2}$ Institute of Human Physiology and Clinical Experimental Research, Semmelweis University, 1094-Budapest, Tüzoltó u. 37-47., Hungary

${ }^{3}$ Department of Radiological Sciences, Graduate School of Medicine and Pharmaceutical Sciences, University of Toyama, 930-0194-Toyama, 2630 Sugitani, Japan

\begin{abstract}
Our aim is to describe the physical and physiological effects of local modulated electro-hyperthermia (mEHT). The method concentrates on the energy absorption of cluster rafts of the plasma membrane. The targeted cluster contains transmembrane proteins, which can form coherent working voltage-gated ion channels and/or TRP receptors in one domain. This targeting is analogous to nanoparticle heating, except this uses readily available nanoparticles on the cell membrane instead of the artificially placed nano-object to induce selective energy absorption from the outside field. In the discussed non-artificial nanoparticle heating, selectivity is the consequence of the synergy of various interactions embedded into each other in their effective volume in macro-, micro- and nano-ranges.
\end{abstract}

Keywords: Membrane rafts; TRP receptors; Selection; RF current; Cancer; Hyperthermia

\section{Introduction}

Modulated electro-hyperthermia (mEHT, trade-name: oncothermia) is a type of hyperthermia applied in oncology for the curative and palliative treatment of malignant tumours [1]. It is highly selective for malignant cells, and solves the targeted therapy mostly on cancer cells. The selection is solved by the modulated radiofrequency carrier signal $(13.56 \mathrm{MHz})$. The electronic excitation allows special laddering-type selection, step-by-step focusing from macro- to microand finally to the nano-range. The method has been widely applied in numerous research activities [2], and also in clinical practice [3-7]. Our objective in this paper is to discuss the mechanism of nanoscopic heating in detail, allowing a better understanding of the cancer-killing effect of mEHT.

The macroscopic selection of mEHT is based on certain differences in the metabolic rate of malignant and healthy cells (Warburg effect [8-10]). The high glucose influx of malignant cells changes their extracellular surrounding, where the ionic concentration increases dramatically, creating a more conductive path directing the electric current and focusing automatically on the malignant lesion.

The microscopic selection is determined by the differences of the dielectric constant of the extracellular electrolyte in the immediate vicinity of the malignant and healthy cells (Szentgyorgyi effect [11]). The dielectric permittivity of the extracellular electrolyte depends on its molecular order and fixed bonds, which are mostly absent around malignant cells [1214]. Healthy cells have homeostatic electrolyte concentrations in different regions, while the cancer cells definitely modify it, losing the connections (adherent and junctional) between cells, which disorients part of the order and increases the electric permeability [15]. The dielectric forces decrease along with the increased dielectric permittivity, adding to the separation of the cells (autonomy) [16,17]. The energy which hits a cell in the healthy network can be shared immediately with the connected neighbours, while this mechanism is mostly missing in individual autonomic malignant cells; they disseminate the energy slower, using only thermal effects.

Malignant tissue has a special and distinguishable pattern, which is studied by pathology. In addition to the above localisations, mEHT also uses these structural differences for selection (pathological pattern recognition) of the malignant and healthy tissues (fractal physiology [18]).

The cellular membranes have further dielectric specialties in their parts in the nanoscopic range (Schwan effect [19]). The membranebound water has the upper part of the $\beta$-dispersion, denoted by $\delta[20,21]$, meaning that this part is highly selective for the various cell membrane states. In particular, all of the electrolyte and membrane properties differ between malignant and healthy tissue $[22,23]$. The proper selection uses the dipole relaxation of beta-dispersion connected to membrane-bound water [24]. This allows the zero-order electric-field action, which has no noise-induced thermal limit of the field [25]. The huge local dielectric permittivity of the transmembrane proteins and their clusters (rafts), are active in the electro-orientation of cells [26].

Artificial (standard) nanoparticle heating has very good selectivity, due to the targeted absorption of the locally-heated nanoparticles on cell membranes.

The electric field strength gain (ratio of the induced field in the material compared to the outside inducer field) is the largest in the cell membrane, as we know from in silico models [27]. The gain of up to a few tens of $\mathrm{MHz}$ is constantly $\approx 5 \cdot 10^{3}$, and it decreases by power law $1 / \mathrm{f}$ approaching higher frequencies [21]. In the case of more realistic tissue models, the gain of the membrane depends on the position of the cell in the tissue, but it is not lower than $10^{2}$ in tissue arrangements [28]. In the case of cancer cells, the intracellular gain is the same as in noncancerous cells, but the membrane gain in malignant cells is double that of their healthy counterparts [22].

The described concept of cell membrane rafts [29] is well studied nowadays in the relevant literature [30]. Important observations indicate a coherent cluster structure of a large number $\left(\sim 10^{5}\right)$ of voltage-gated ionic channels [31,32], which could have transient receptor potential receptors (TRP, especially the TRPV subtypes) in one temperature-sensing domain [33]. These clusters are the targets of our

*Corresponding author: Prof. A. Szasz, Department of Biotechnics, St. Stephen University, 2100-Gödöllö, Páter K. u. 1, Hungary, Tel: +36-23-555-510; Fax: +3623-555-515; E-mail: biotech@gek.szie.hu

Received July 22, 2015; Accepted September 05, 2015; Published September 12 2015

Citation: Vincze Gy, Szigeti Gy, Andócs G and Szász A. (2015) Nanoheating without Artificial Nanoparticles. Biol Med (Aligarh) 7: 249. doi: 10.4172/09748369.1000249

Copyright: @ 2015 Vincze Gy, et al. This is an open-access article distributed under the terms of the Creative Commons Attribution License, which permits unrestricted use, distribution, and reproduction in any medium, provided the original author and source are credited. 
method targeting the 'built-in' nanoparts of the membrane for heating selectively. Selection is based on the high specific absorption rate (SAR) of the nanoparts. The targets of heating could be these clusters of cell membrane in malignant cells.

Amongst the receptors belonging to the TRPV family, a strong correlation between clinicopathological findings and expression of different TRPV channels (e.g. TRPV1, TRPV2 and TRPV6) in cancer growth has recently been reported [34,35]. Changes in TRPV1 expression occur during the development of human urothelial cancer [36]. Recently, the role of TRPV1 mRNA down-regulation as a negative prognostic factor in patients with bladder cancer has been assessed [37]. However, increased TRPV1 expression is suggested as an inhibitory factor of cancer development [38]. Therefore, we hypothesised that any factors which can exhaust TRPV1 receptor expression can reduce tumorigenesis.

The TRPV1 ion channels are capable of exercising a regulatory effect on intracellular calcium concentration, which, in turn, plays a key role in cell function. The short-term regulation of cell function depends primarily on several cell components which are affected by the free calcium ions in the cytosol. However, long-term activation of the TRPV1 receptor and the consequent increase in intracellular calcium concentration results in cytotoxicity. Moderate heat $\left(\geq 43^{\circ} \mathrm{C}\right)$ can activate TRPV1, demonstrating that thermal heat and the pungent ingredient in 'hot' foods elicit their effects through the same channel [39].

Non-excitable cells also have TRP channels [40], and thermosensors are one of these groups. Thermosensors are charged transmembrane proteins which are displaced by heat'. TRP is an 'electrochemical diode' which rectifies ionic transport through the membrane and is loaded in the closing direction under standard (resting, negative membrane potential, cell is positive outside) physiological conditions. These channels are primarily involved in $\mathrm{Ca}^{2+}$ transport. Due to their closed resting (default) value, the $\mathrm{Ca}^{2+}$ influx into the cell is rather limited. The diode characteristics (rectification parameters) are different in hot- [28] and cold-sensing [28] TRPs. Hot-sensing shifts the diode to the opening direction [41], while cold-sensing shifts the diode in the opposite direction [42], to the closing side. The regulation is dynamic, and the transmembrane protein is displaced by the temperature action [43]. The TRP receptors could be clustered in membrane rafts which are effective thermosensors of the cell [27]. These domains could considerably increase $\mathrm{Ca}^{2+}$ influx to the cytoplasm by heating.

The concentration of intracellular $\mathrm{Ca}^{2+}$ is low under normal conditions. However, $\mathrm{Ca}^{2+}$ has an important controlling function in the homeostatic balance of proliferation. Intracellular $\mathrm{Ca}^{2+}$ concentration affects the cellular decision between division and apoptosis [44]. The balance of proliferation and apoptosis is well regulated by $\mathrm{Ca}^{2+}$ entry. The Ca balance also acts on cell membranes; the membrane potential decreases in cells with enhanced concentrations of $\mathrm{Ca}^{2+}$ in the cytoplasm $[45,46]$. The lowered membrane potential, however, is pro-proliferative, both in healthy and malignant cases [47]. Malignant differentiation increases $\mathrm{Ca}^{2+}$ entry [48], which is pro-proliferative, reaching an oscillatory equilibrium of $\mathrm{Ca}^{2+}$. Extracellular ATP induces oscillations of intracellular $\mathrm{Ca}^{2+}$ and membrane potential [49]. The ATP released from inflamed, damaged or metabolically impaired cells represents a 'danger signal' that plays a major role in activating the innate immune system, and intracellular Ca-overload also promotes apoptosis [50].

The aim of this study is to demonstrate a mathematical model which describes the TRP receptor function between heat and carcinogenesis.

\section{Materials and Methods}

The cellular membrane could be considered as fluid mosaic [51], where the transmembrane proteins move by lateral diffusion [52]. The inhomogeneous electric field in the case of mEHT acts on transmembrane proteins by dielectrophoretic force, drifting them forwards. This interaction is rather selective, because the dielectric permittivity of the transmembrane proteins is at least two orders of magnitude higher than the membrane permittivity in which they move [53]. As a consequence, the direction of the drift movement points to higher energy density, where the specific energy absorption (SAR) is also higher. SAR increases on these points of the membrane (microcontacts), and consequently the increase in local temperature also affects the local TRPs ('Micro-contact' means the place on the cellular membrane where the electric field strength induced by the outside field is the highest. This point is roughly identical to the in/out point of the RF current or its imaginary part in direct mechanical contact with the neighbouring cells). As a consequence, the heat-sensing TRPs displace to the opening while the cold-sensing TRPs displace to the closing direction. The motility of TRPs is greater in the membrane of malignant cells [54], facilitating more TRPs in the high SAR places, allowing the certainly high $\mathrm{Ca}^{2+}$ influx to the cytoplasm. This changes the homeostatic equilibrium of the actual cell, promoting apoptotic cell death, as observed in mEHT treatments $[55,56]$. The increased BAX level in the affected cells [55] also indicates this apoptotic effect.

In this calculation, we assume the equal dielectric and diffusion properties of the various ion channels. In this case, the following equations describe the above drifting process:

$$
\begin{aligned}
& \frac{\partial \rho}{\partial t}+\operatorname{div} \mathbf{J}=0, \\
& \mathbf{J}=\mathbf{J}_{\text {drift }}+\mathbf{J}_{\text {diff }}=-\mu \mathbf{F} \rho-D \operatorname{grad} \rho
\end{aligned}
$$

where $\rho(\mathbf{r}, t)$ is the concentration of the ion channels in the $\mathbf{r}$ point of the membrane in the $t$ time, $\mathbf{J}(\mathbf{r}, t)$ is the resultant current density of the ion channels, $\mathbf{J}_{\text {drift }}(\mathbf{r}, t)$ and $\mathbf{J}_{\text {diff }}(\mathbf{r}, t)$ are the drift and diffusion current density, respectively, $\mu$ is the motility of $t$ ion channel with $D$ diffusion constant in the membrane and $\mathbf{F}$ is the dielectrophoretic force, which is $[57,58]$ :

$$
\mathbf{F}(\mathbf{r}, t)=-a^{3} \varepsilon \frac{\varepsilon_{T R P}-\varepsilon}{\varepsilon_{T R P}-2 \varepsilon} \operatorname{grad} \frac{[\mathbf{E}(\mathbf{r}, t)]^{2}}{2}
$$

where $a$ is the radius of the ionic channel, $\varepsilon$ and $\varepsilon_{T R P}$ are the dielectric permittivity of the membrane and the TRP channels, respectively, and $\mathbf{E}(\mathbf{r}, t)$ is the electric field strength in the $\mathbf{r}$ point of the membrane at $t$ time. Since the relation of $\varepsilon<\varepsilon_{T R P}$ holds, from Eq. (2), a simple form of dielectrophoretic force follows:

$$
\mathbf{F}(\mathbf{r}, t)=-\operatorname{grad}\left\{a^{3} \varepsilon \frac{[\mathbf{E}(\mathbf{r}, t)]^{2}}{2}\right\}
$$

where we assume that the dielectric permittivity, $\varepsilon$, of the membrane does not depend on the position of the membrane. Due to the radiofrequency supply, the electric field is time-dependent. Let us 
Citation: Vincze Gy, Szigeti Gy, Andócs G and Szász A. (2015) Nanoheating without Artificial Nanoparticles. Biol Med (Aligarh) 7: 249. doi: 10.4172/0974-8369.1000249

consider the average of the field in a period of time in Eq. (1), since the expected time constants in the processes are larger. In this case, Eq. (1) and its connected values are:

$$
\begin{aligned}
& \frac{\partial\langle\rho\rangle}{\partial t}+\operatorname{div}\langle\mathbf{J}\rangle=0, \\
& \langle\mathbf{J}\rangle=\left\langle\mathbf{J}_{\text {drift }}\right\rangle+\left\langle\mathbf{J}_{\text {diff }}\right\rangle=\mu\langle\mathbf{F}\rangle-\operatorname{Dgrad}\langle\rho\rangle, \\
& \langle\mathbf{F}\rangle=-\operatorname{grad}\left\{a^{3} \varepsilon \frac{\mathbf{E}_{\text {eff }}^{2}(\mathbf{r})}{2}\right\} \\
& \mathbf{E}_{\text {eff }}(\mathbf{r}):=\sqrt{\left\langle[\mathbf{E}(\mathbf{r}, t)]^{2}\right\rangle}
\end{aligned}
$$

where we introduced the effective value of the electric field and the $\triangleleft$ signs denote the averages. We are looking for the stationary solution of equations (4) when the resultant current density is zero; the drift and diffusion current densities are equal. In this case, we have:

$$
\begin{aligned}
& \frac{\partial\langle\rho\rangle}{\partial t}+\operatorname{div}\langle\mathbf{J}\rangle=0, \\
& \langle\mathbf{J}\rangle=\left\langle\mathbf{J}_{\text {drift }}\right\rangle+\left\langle\mathbf{J}_{\text {diff }}\right\rangle=-\mu\langle\mathbf{F}\rangle\langle\rho\rangle-\operatorname{Dgrad}\langle\rho\rangle, \\
& -\operatorname{Dgrad}\left\{\frac{\mu}{D} a^{3} \varepsilon \frac{\mathbf{E}_{e f f}^{2}(\mathbf{r})}{2}-\ln \langle\rho\rangle\right\}=0 \Rightarrow\langle\rho\rangle=\left\langle\rho_{0}\right\rangle e^{a^{3} \varepsilon \frac{\mathbf{E}_{\text {eff }}^{2}(\mathbf{r})}{2 k T},} \\
& \frac{1}{k T}=\frac{\mu}{D}
\end{aligned}
$$

where $k$ is the Boltzmann constant, $T$ is the temperature of the membrane (introduced by Einstein's relation), and $\left\langle\rho_{0}\right\rangle$ is the ion channel density when the applied outside field strength is zero.

The increase in the density of ion channels is expected at the high field-strength micro-contact places, when the following condition is valid:

$$
0<<a^{3} \varepsilon \frac{\mathbf{E}_{e f f}^{2}(\mathbf{r})}{2 k T}
$$

This criterion is a simple consequence of Eq. (5). When this value in Eq. (6) is 1, the density of ion channels is nearly three times higher than the field-free equilibrium concentration, and the field strength would in this case be $E \approx 0{ }^{7} \mathrm{~V} / \mathrm{m}$ [31], which is unrealistic. Consequently, this model failed.

\section{Results}

The polarisability of the biopolymers is well known [59]. The fieldstrength of the cell membrane is huge: $E \approx 0{ }^{7} \mathrm{~V} / \mathrm{m}$; consequently, its effect on the ionic channels is expected and it will likely polarise the transmembrane proteins until their saturated polarisation value is reached because the rotational diffusion is stronger in the membrane than the translational [60] diffusion. Consequently, the transmembrane proteins have to have strong enough dipoles to block their rotation, which would likely be due to the thermal excitation. It would cause definite disturbances of their functions, so that saturation by the extreme huge membrane field maximises the electric dipole moment of the transmembrane proteins, ensuring their stability. The mathematical condition of the stability is:

$$
1<<\frac{E_{m} p_{i c h}}{k T}
$$

where $p_{T R P}$ is the dipole moment of the TRP. To estimate the value of this dipole moment, we consider the low frequency permittivity of the muscle tissue, which has a value in the range of $0^{7}$ [60]. Assuming a linear polarisation effect until saturation polarisation is reached, we obtain for the value of saturation polarisation vector:

$$
\begin{aligned}
& P=\varepsilon_{0}\left(\varepsilon_{T R P}-1\right) E_{m} \cong 10^{-11} \times 10^{7} \times 10^{7}=10^{3} \mathrm{As} / \mathrm{m}^{2} \\
& P=\varepsilon_{0}\left(\varepsilon_{T R P}-1\right) E_{m} \cong \mathbb{0}{ }^{-1} \times \mathbb{0}{ }^{7} \times \mathbb{0}{ }^{7}=\mathbb{0}{ }^{3} \& / m^{2} \text {. }
\end{aligned}
$$

Choosing the volume of the ionic channel on the realistic $V_{T R P} \cong 10^{-24} \mathrm{~m}^{3}$, the dipole momentum of the channel is $p_{T R P}=P_{T R P}=0^{3} \times \mathbb{0}^{-1}=\mathbb{0}^{-1} A m s$. With this assumption, we obtained a definite high value for the critical value in Eq. (7):

$$
\frac{E_{m} p_{T R P}}{k T} \cong 10^{7}
$$

When the electric field in the membrane is $E_{m}$, and assuming the isotropy of polarisability of the channel, then in the saturated case, the polarisation vector turns to the direction of the resultant electric field keeping its absolute value (Figure 1). When no saturation occurs, the forced rotational orientation will not happen.

When $E<E_{m}$, then the $E$ field induces $P(E)$ value of the polarisation vector, and:

$$
P(E) \cong P \frac{E}{E_{m}}
$$

Due to the small angles, the polarisation $\mathbf{P}(\mathbf{E})$ could be well approached as parallel with field $\mathbf{E}$. This allows the two cases to be described identically. In this way, the induced dipole momentum of the TRP channel is:

$$
p_{T R P}(E)=V_{T R P} P(E) \cong P V_{T R P} \frac{E}{E_{m}}=p_{T R P} \frac{E}{E_{m}}
$$

With this, the dielectrophoretic force acting on the TRP channel will be:

$$
\mathbf{F}(\mathbf{r}, t)=\left[\mathbf{p}_{T R P}(\mathbf{E}(\mathbf{r}, t)) \operatorname{grad}\right] \mathbf{E}(\mathbf{r}, t)=\frac{p_{T R P}}{E_{m}} \operatorname{grad} \frac{\mathbf{E}^{2}(\mathbf{r}, t)}{2}
$$

Also, the drift diffusion equations according to Eq. (4) will be:

$$
\begin{aligned}
& \frac{\partial\langle\rho\rangle}{\partial t}+\operatorname{div}\langle\mathbf{J}\rangle=0, \\
& \langle\mathbf{J}\rangle=\left\langle\mathbf{J}_{\text {drifit }}\right\rangle+\left\langle\mathbf{J}_{\text {diff }}\right\rangle=\mu\langle\mathbf{F}\rangle-\operatorname{Dgrad}\langle\rho\rangle, \\
& \langle\mathbf{F}(\mathbf{r}, t)\rangle=\frac{p_{T R P}}{E_{m}} \operatorname{grad} \frac{\left\langle\mathbf{E}^{2}(\mathbf{r}, t)\right\rangle}{2}=\frac{p_{T R P}}{E_{m}} \operatorname{grad} \frac{\mathbf{E}_{e f f}^{2}(\mathbf{r})}{2} \\
& \mathbf{E}_{e f f}(\mathbf{r}):=\sqrt{\left\langle[\mathbf{E}(\mathbf{r}, t)]^{2}\right\rangle}
\end{aligned}
$$




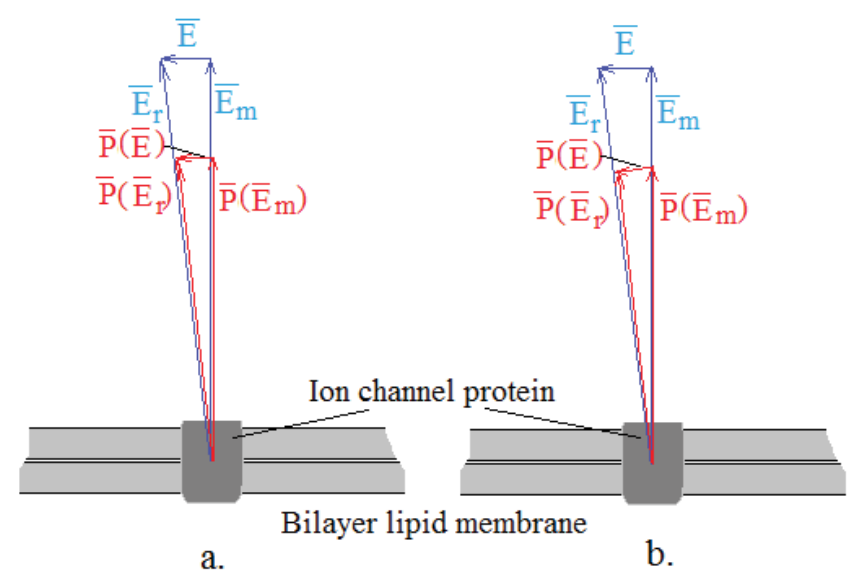

Figure 1: For calculation of the electrophoretic force (the angle of the resulting $P(E)$ vector is small and negligible in comparison to the relative large components ).

We solve these equations in the stationary case when the resultant current density is zero. Therefore, when the drift and diffusion current densities eliminate each other, then:

$$
\begin{aligned}
& \frac{\partial\langle\rho\rangle}{\partial t}+\operatorname{div}\langle\mathbf{J}\rangle=0, \\
& \langle\mathbf{J}\rangle=\left\langle\mathbf{J}_{\text {drift }}\right\rangle+\left\langle\mathbf{J}_{\text {diff }}\right\rangle=-\mu\langle\mathbf{F}\rangle\langle\rho\rangle-\operatorname{Dgrad}\langle\rho\rangle, \\
& -\operatorname{Dgrad}\left\{\frac{\mu}{D} \frac{p_{T R P}}{E_{m}} \operatorname{grad} \frac{\mathbf{E}_{e f f}^{2}(\mathbf{r})}{2}-\ln \langle\rho\rangle\right\}=0 \Rightarrow\langle\rho\rangle=\left\langle\rho_{0}\right\rangle e^{\frac{p_{R R P} \mathbf{E}_{e f}^{2}(\mathbf{r})}{2 k T}}, \\
& \frac{1}{k T}=\frac{\mu}{D}
\end{aligned}
$$

Similarly to Eq. (5), the expected concentration of the ionic channels in the high SAR micro-contacts could be from Eq. (13), when:

$$
0<<\frac{p_{i c h}}{E_{m}} \frac{\mathbf{E}_{e f f}^{2}(\mathbf{r})}{2 k T}
$$

Using the value in Eq. (8), we obtain at $E_{\text {eff }}=4 \times 0{ }^{3} \mathrm{~V} / \mathrm{m}$ a relatively small field strength:

$$
\frac{p_{T R P}}{E_{m}} \frac{\mathbf{E}_{e f f}^{2}(\mathbf{r})}{2 k T} \cong 1
$$

when the concentration is at least three times higher than the field-free equilibrium. This $\boldsymbol{E}$ value of the field strength is small in the membrane, due to the fact that the membrane gain at $13.56 \mathrm{MHz}$ (carrier frequency of $\mathrm{mEHT}$ ) is more than 100 [21,61]. In this consideration, the $E_{\text {eff }}=4 \times 0{ }^{3} \mathrm{~V} / \mathrm{m}$ field could be obtained by $40 \mathrm{~V} / \mathrm{m}$ outside the electric field and causes a $0.04 \mathrm{mV}$ field on the membrane. When considering the physiological safety limit for the outside field, which is $200 \mathrm{~V} / \mathrm{m}$, we get:

$$
\frac{p_{T R P}}{E_{m}} \frac{\mathbf{E}_{e f f}^{2}(\mathbf{r})}{2 k T} \cong 25
$$

(This could be reached by $7 \times 0 \quad$ time concentration gain.)

According to these considerations, there is a realistic physical basis in having large ion channel concentrations in the areas of the membrane where the SAR is large.

Due to safety reasons, /standards allow $2 \times 0{ }^{4} \mathrm{~V} / \mathrm{m}$ outside field strength. This could induce only $2 \times 0{ }^{4} \mathrm{~V} / \mathrm{m}$ field strength in the membrane, which is negligible compared to the huge $0^{7} \mathrm{~V} / \mathrm{m}$ field strength there. Calculating conductivity of the membrane with $\sigma_{m} \cong 3 \times 0^{-7} \mathrm{~S} / \mathrm{m}$, the connected SAR value is $S A R \cong 0{ }^{7} \mathrm{~W} / \mathrm{m}^{3}$ dissipation, which is considerably larger (a thousandth of this value could heat a tumour up to $45^{\circ} \mathrm{C}$ ). Nanoparticle heating often uses one to two orders of magnitude higher SAR than this certainly huge value. The phospholipid, the membrane's base material, is a very effective heat and electric isolator; therefore, the observed (at least not too great) conductivity properties must be produced by the transmembrane proteins and their channel constructions. When these are homogeneously distributed in the membrane, they heat it equally everywhere. The metabolic heat liberated from the cell machinery interacts with the environment in this way. The membrane conductivity could be increased locally by the concentration of the ion channels and the transmembrane proteins as a part of the membrane. Due to the stable membrane potential, in those places where conductivity is increased, the SAR also increases, while at the expense of this, other parts have a lower load. When the direction of ion channels in relation to the membrane does not change during their drift, the membrane conductivity ( $\sigma_{\text {mlocal }}$ ) will be proportional to the local concentration of these channels. Hence:

$$
\sigma_{\text {mlocal }}=\sigma_{m} \frac{\langle\rho\rangle}{\left\langle\rho_{0}\right\rangle}=\sigma_{m} e^{\frac{p_{T R P}}{E_{m}} \frac{\mathbf{E}_{e f f}^{2}(\mathbf{r})}{2 k T}}
$$

where $\sigma_{m}$ characterises the membrane conductivity when the channel distribution is homogenous. It can be assumed that the SAR gain at least follows the gain of the conductivity, so:

$$
S A R_{\text {local }}=\sigma_{\text {mlocal }} E_{m}^{2}=\sigma_{m} E_{m}^{2} e^{\frac{p_{T R P} \mathbf{E}_{e f f}^{2}(\mathbf{r})}{E_{m}}}=S A R e^{\frac{p_{T R R}}{E_{m}} \frac{\mathbf{E}_{e f f}^{2}(\mathbf{r})}{2 k T}}
$$

where SAR is the value when the ion channels are distributed homogeneously. Using the conditions of Eq. (16), this means $7 \times \mathbb{0}$ -times larger SAR at the concentration of the channels. This obviously increases the membrane temperature by a few centigrade without the addition of external SAR. The local temperature increase opens the heat-sensitive TRP channels, which further increase the local SAR and gains of the $\mathrm{Ca}^{2+}$ ion influx to the given cell.

The heat conduction coefficient of the extra- and intracellular electrolyte is considered equal in the first approximation [62]. We also assume that the large SAR induced by the concentrated channel distribution in a micro-contact is small, cylinder-shaped, and has no heat exchange on its jacket, and also that the heat flux conducted and flowing on the cylinder is connected to free space at its two ends (Figure 2). Let us consider a $\Delta T$ heat increase due to the $I_{q}$ heat flux at $\lambda$ heat conduction value (Figure 2).

In this case: 
Citation: Vincze Gy, Szigeti Gy, Andócs G and Szász A. (2015) Nanoheating without Artificial Nanoparticles. Biol Med (Aligarh) 7: 249. doi: 10.4172/0974-8369.1000249

Page 5 of 9

$$
\Delta T=I_{q} R_{q}
$$

where $R_{q}$ is the thermal resistance of the cylinder, which could be determined from the stationary electric and thermal analogy, as follows:

$$
R_{q}=\frac{R}{\rho \lambda}
$$

where $R$ is the electric resistivity of a circle plate having $a$ radius and $\rho$ specific resistivity [63]

$$
R=\frac{\rho}{2 a}
$$

In the stationary state, the connection between the $S A R_{\text {local }}$ and the $I_{q}$ heat flux on the cylinder is:

$$
I_{q}=\frac{S A R_{\text {local }} a^{2} d}{2}
$$

where the $S A R_{\text {local }}$ is approximated as constant due to the small volume of the cylinder. From Eq. (19) using Eqs. (18), (20) and (21) we get:

$$
\Delta T=I_{q} R_{q}=\frac{\pi}{4} \frac{S A R_{\text {local }} a d}{\lambda}=\frac{\pi}{4} \frac{a d}{\lambda} \sigma_{m} E_{m}^{2} e^{\frac{p_{T R P} \mathbf{E}_{e f f}^{2}(\mathbf{r})}{E_{m}}}
$$

$$
\text { Calculating an example: when } \Delta T=7 \mathrm{~K} \text {, and } a=1 \mu \mathrm{m}
$$$$
d=0 \mathrm{~m}, \lambda=0,6 \mathrm{~W} / \mathrm{K}
$$
$E_{m}=0{ }^{7} \mathrm{~V} / \mathrm{m}$, we get:

$$
\sigma_{m}=3 \times 0{ }^{-7} S / m
$$

$$
e^{\frac{p_{T R P} \mathbf{E}_{e f f}^{2}(\mathbf{r})}{E_{m}} 2 k T}=1.75 \times 10^{7} \rightarrow \frac{p_{T R P}}{E_{m}} \frac{\mathbf{E}_{e f f}^{2}(\mathbf{r})}{2 k T}=16.6
$$

Producing this value, we need $E_{\text {eff }}=\mathbf{6} \times \mathbf{0}{ }^{3} \mathrm{~V} / \mathrm{m}$ locally on the membrane and $E=160 \mathrm{~V} / \mathrm{m}$ outside the applied electric field. These are actually possible values for practical application. In the case of special pink noise modulation, very high effective field strengths could

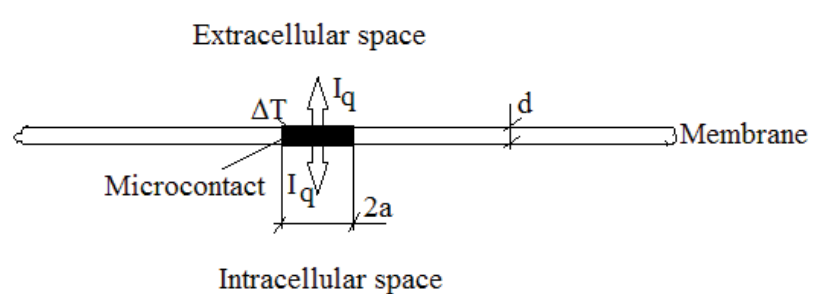

Figure 2: For calculating the increase in local membrane temperature. occur (especially, when very long noise representation is given for the modulation. This is the consequence of Shannon's sampling theorem II).

The local temperature increase would be $44^{\circ} \mathrm{C}$ when the example above is applied. Thermolysis occurs at this temperature [64]. This is shown in Figure 3 [52].

The increased temperature melts the membrane lipids and starts to dissolve in the surrounding electrolytes, thus changing the configuration of the membrane lipids, resulting in the growth of the molecular permeability of the targeted membrane. This effect induces a further local SAR increase which damages the membrane. It is possible that the tumour treating fields effect [65] (NovoTTF, [66]) is based on this phenomenon.

The time function of a $\Omega_{0}$ circular frequency harmonic carrier signal, which is amplitude modulated by a carrier frequency sinus signal, is:

$$
u(t)=U_{0}[1+m \sin (\omega t+\phi)] \sin \Omega_{0} t
$$

where $m$ is the modulation depth. The spectrum of this signal is shown in Figure 4.

Therefore, the effective potential is:

$$
u_{\text {eff }}^{2}=\frac{U_{0}^{2}}{2}+m^{2} \frac{U_{0}^{2}}{4}
$$

Consequently, the modulation increases the effective value of the potential, and thus increases the effective electric field strength. As a consequence, it increases the local conductivity by Eq. (17) and the local SAR by Eq. (18). In the case of noise modulation, which has a continuous frequency spectrum (also it has no measurable discrete line in its spectrum), the local conduction and SAR could be increased even further.

Let us show an example of a modulated signal as below, where $x(t)$ is pink noise.

$$
u(t)=x(t) U_{0} \sin \Omega_{0} t
$$

The noise power spectrum of the pink noise in $X(\omega) X^{*}(\omega)=\frac{A}{\omega}$ frequency interval is:

$$
X(\omega) X^{*}(\omega)=\frac{A}{\omega}
$$

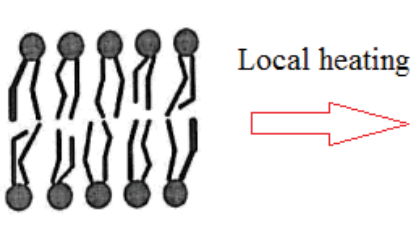

$$
37^{\circ} \mathrm{C}
$$

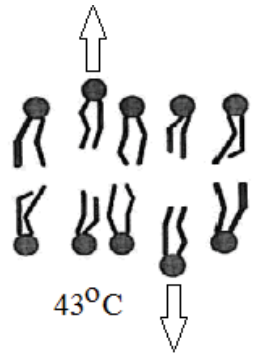

Normal cell membrane

Thermolysis

Figure 3: Conceptual view of thermally-driven membrane permeabilisation. 


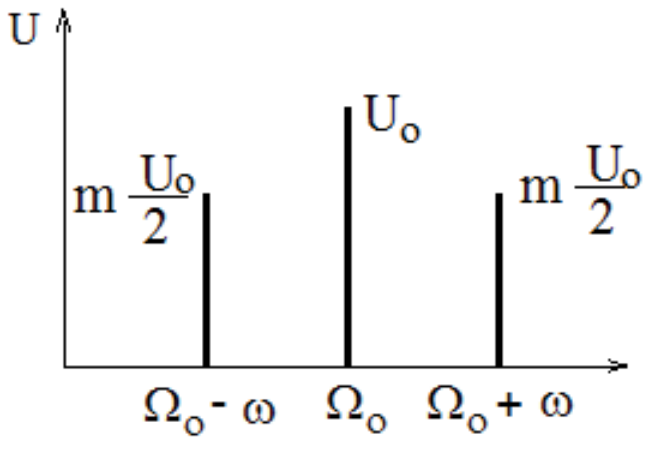

Figure 4: The frequency spectrum of an amplitude modulated harmonic signal.

In this case, the effective value of the modulated signal is:

$$
u_{e f f}^{2}=\frac{U_{0}^{2}}{2}+2 A \ln \frac{\omega_{f}}{\omega_{a}}
$$

Which in the case of $\omega_{a} \rightarrow 0$ goes to infinity: $u_{e f f}^{2} \rightarrow \infty$.

Consequently, this type of pink noise modulation is excellent for local heating (other important effects of pink noise modulation are discussed elsewhere [11]).

A further consequence of modulation with harmonic signals is the higher probability of the opening of voltage-gated ion channels by stochastic resonance [67]. With this, there is a considerable increase in the membrane conductivity, the ion influxes and the local SAR. Since the multiple voltage-gated ionic channels are concentrated in the dense cluster, multiple stochastic resonance frequencies exist there. It is possible that the 'magic' frequencies in [68-70] could be explained in a similar way.

The dynamic (time fractal) behaviour is the effective information exchange between the cells in space and also in time. Due to the malignant autonomy, the collective communication signals (called social signal) are broken [71]. The social signals and their correlation length is determined by different factors, among which is an energy pack-like information transfer e.g. [72-75]. Consequently, the normal (healthy homeostatic) biological processes could be described by selfsimilar function classes based on the dynamic observations for longrange correlation lengths [76,77]. The missing information exchange could be re-established by the forced delivery of information, for which the best is modulation of the RF carrier. The famous Adeywindow, published in the early 1990s, was the first proof of the special modulation effects $[78,79]$. The modulation of RF carrier frequency then started to be used [80], and became an important new method for cancer therapies [81]. Numerous clinical results show its efficacy [8285], and it was applied in oncothermia for dynamic selection from the late 1980s. The support of modulation is clearly shown in experimental results [86]. The carrier frequency delivers the information (modulation frequencies), since the cancer cells are much less 'transparent' at these frequencies than their healthy counterparts. Malignant cells are heated up by the selectively absorbed energy. The applied modulation helps to localise the tumour border, it helps to 'clear' the contours, whilst (most importantly) helping to select (self-focus) the energy intake, exciting numerous signal pathways on the outer cell membrane.

\section{Appendix: Temperature On Membrane Rafts}

The temperature from SAR in the stationary process can be derived from the non-linear Pennes equation [87]. Blood perfusion, metabolic heat and temperature dependence of the target leads to non-linearity. The simple equation in its general form is [88]:

$$
\rho c \frac{\partial T}{\partial t}+c_{b} \rho_{b} w_{b}(T)\left(T-T_{b}\right)=\lambda \Delta T+p_{0} S A R(T)+q_{0} 1,1^{(T-36,6)}
$$

The generalisation appears in the second term on the right side of the equation as we note the SAR from the heating process of the target resulting from the change in conductivity.

If we take the stationary case and neglect the part obtained from the conduction, then we get:

$$
c_{b} \rho_{b} w_{b}(T)\left(T-T_{b}\right)=p_{0} S A R(T)+q_{0} 1,1^{(T-36,6)}
$$

From this, the increase in temperature compared to the temperature of the blood is:

$$
\Delta T=\left(T-T_{b}\right)=\frac{p_{0} S A R(T)+q_{0} 1,1^{(T-36,6)}}{c_{b} \rho_{b} w_{b}(T)}
$$

With no consideration of the SAR and the metabolic heat, we come to:

$$
\Delta T=\left(T-T_{b}\right)=\frac{p_{0}}{c_{b} \rho_{b} w_{b}(T)}
$$

where $p_{0}$ is the SAR of the target. Here, the blood perfusion rate is given in the SI system, which is: $\frac{m^{3}}{\sec ^{3}}$. The physiological adequate unit is: $\frac{t h}{\text { perc } 100 \mathrm{~g}}$. To converse between these two:

$$
w_{b}(T)=\frac{10^{-6}}{6} w_{b f i z i o l}(T)
$$

Putting this into the previous equation:

$$
\begin{aligned}
& \Delta T=\frac{p_{0}}{c_{b} \rho_{b} w_{b}(T)}=\frac{p_{0}}{1,1 \times 10^{3} \times 4,5 \times 10^{3} \times \frac{10^{-6}}{6} w_{b f i z i o l}(T)}= \\
& =1.3 \frac{S A R}{w_{b f i z i o l}(T)}
\end{aligned}
$$

which could be due to the different database applications.

In case the temperature rises when the heating power is switched on, the simplified Pennes equation can be used: 
Citation: Vincze Gy, Szigeti Gy, Andócs G and Szász A. (2015) Nanoheating without Artificial Nanoparticles. Biol Med (Aligarh) 7: 249. doi: 10.4172/0974-8369.1000249

$\rho c \frac{\partial T}{\partial t}+c_{b} \rho_{b} w_{b}\left(T-T_{b}\right)=p_{0}$

$\rho c \cong c_{b} \rho_{b}$

consequently:

$\frac{\partial\left(T-T_{b}\right)}{\partial t}+\frac{1}{\tau}\left(T-T_{b}\right)=\frac{p_{0}}{\rho c}$,

$\tau=w_{b}^{-1}$

Therefore, the solution is:

$$
\Delta T=\frac{\tau}{\rho c} p_{0}\left(1-e^{-\frac{t}{\tau}}\right)
$$

From here, the starting speed of the temperature rise is:

$$
\left.\frac{\Delta T}{t}\right|_{t=0}=\frac{\tau}{\rho c} p_{0}\left(1-e^{-\frac{t}{\tau}}\right) \cong \frac{p_{0}}{\rho c}
$$

Substituting the values:

$$
\left.\frac{\Delta T}{t}\right|_{t=0}\left[C^{0} / \mathrm{min}\right]=60 \frac{S A R[\mathrm{~W} / \mathrm{kg}]}{c} \cong \frac{S A R[\mathrm{~W} / \mathrm{kg}]}{67}
$$

Hence, the measurement of the speed of temperature rise at the beginning of heating determines the SAR according to (11).

This makes it possible to calculate the SAR in the target by measuring the speed of the temperature rise in the neighbouring healthy tissue (assuming equal temperature) and to calculate the SAR in the malignant neighbourhood.

The switching-off of the heating power can be approximately described with the following Pennes equation:

$$
\begin{aligned}
& \frac{\partial\left(T-T_{b}\right)}{\partial t}+\frac{1}{\tau}\left(T-T_{b}\right)=0, \\
& \tau=w_{b}^{-1}
\end{aligned}
$$

The solution is:

$$
\Delta T(t)=\left(T-T_{b}\right)=\frac{\tau}{\rho c} p_{0} e^{-\frac{t}{\tau}},
$$

From this, the $\Delta T(t)$ function, the $\tau$ perfusion time constant and the $w_{b}$ by (8) are also calculable. The starting slope of the clearance of temperature, for example the speed of decrease of the temperature, is:

$$
\left.\frac{d \Delta T}{d t}\right|_{t=0}=-\frac{p_{0}}{\rho c}
$$

which is the same in absolute value as that obtained from (10). Substituting the values, we again obtain (11) with the opposite sign:

$$
\left.\frac{d \Delta T}{d t}\right|_{t=0}\left[C^{0} / \mathrm{min}\right]=-60 \frac{S A R[\mathrm{~W} / \mathrm{kg}]}{c} \cong-\frac{S A R[\mathrm{~W} / \mathrm{kg}]}{67}
$$

The starting speed of the temperature rise and the starting slope of the clearance are equal in their absolute value, independent of the perfusion constant. This means that the starting slope of the switchon and -off depends only on the SAR and is independent from vascularisation.

\section{Acknowledgments}

Authors thank the useful discussions and critical remarks of Prof. Dr. T. Biro (Debrecen University), Dr. N. Meggyeshazi (Semmelweis University) and Dr. Cs. Kovago (St. Istvan University).

\section{References}

1. Szasz A, Szasz N, Szasz O (2010) MEHT - principles and practices, Heidelberg, Dordrecht, Springer.

2. Andocs G, Szasz O, Szasz A (2009) Oncothermia treatment of cancer: from the laboratory to clinic. Electromagn Biol Med 28: 148-165.

3. Szasz A, Szasz N, Szasz O (2013) Local hyperthermia in oncology, chapter in book ed. Huilgol N. Hyperthermia, InTech,USA.

4. Wismeth C, Dudel C, Pascher C, Ramm P, Pietsch T, et al. (2010) Transcranial electro-hyperthermia combined with alkylating chemotherapy in patients with relapsed high-grade gliomas: phase I clinical results. J Neurooncol 98: 395405 .

5. Gadaleta-Caldarola G, Infusino S, Galise I, Ranieri G, Vinciarelli G, et al (2014) Sorafenib and locoregional deep electro-hyperthermia in advanced hepatocellular carcinoma: A phase II study. Oncol Lett 8: 1783-1787.

6. Szasz A (2014) Current status of oncothermia therapy for lung cancer. Korean J Thorac Cardiovasc Surg 47: 77-93.

7. Jeung TS, Ma SY, Lim S, Szasz A (2013) Cases that respond to oncothermia monotherapy, Conference Papers in Medicine, 1-3.

8. Warburg O (1966) Oxygen, The Creator of Differentiation, Biochemical Energetics, Academic Press, New York, 1966; (Warburg O: The Prime Cause and Prevention of Cancer, Revised lecture at the meeting of the NobelLaureates on June 30, 1966 at Lindau, Lake Constance, Germany).

9. Warburg O (1956) On the origin of cancer cells. Science 123: 309-314.

10. Garber K (2004) Energy boost: the Warburg effect returns in a new theory of cancer. J Natl Cancer Inst 96: 1805-1806.

11. Szentgyorgyi A (1968) Bioelectronics, A Study on Cellular Regulations, Defence and Cancer. Acad. Press, London, New York, NY.

12. Gniadecka M, Nielsen OF, Wulf HC (2003) Water content and structure in malignant and benign skin tumors. J Mol Struct 405-410.

13. Beall PT, Asch BB, Chang DC, Medina D, Hazlewood CF (1979) Waterrelaxation times of normal, pre-neoplastic, and malignant primary cell cultures of mouse mammary gland. In: 23rd Annual Meeting of the Biophysical Society, Atlanta, Georgia, USA

14. Chung SH, Cerussi AE, Klifa C, Baek HM, Birgul O, et al. (2008) In vivo water state measurements in breast cancer using broadband diffuse optical spectroscopy. Phys Med Biol 53: 6713-6727.

15. Foster KR, Schepps JL (1981) Dielectric properties of tumor and normal tissues at radio through microwave frequencies. J Microw Power 16: 107-119.

16. Szent-Györgyi A (1980) The living state and cancer. Physiol Chem Phys 12 99-110.

17. Szentgyorgyi A (1998) Electronic Biology and Cancer. Marcel Dekkerm New York.

18. Bassingthwaighte JB, Leibovitch LS, West BJ (1994) Fractal Physiology. Oxford Univ. Press, New York, Oxford.

19. Schwan HP (1963) Determination of biological impedances. Academic Press, New York, NY 6: 323-406. 
Citation: Vincze Gy, Szigeti Gy, Andócs G and Szász A. (2015) Nanoheating without Artificial Nanoparticles. Biol Med (Aligarh) 7: 249. doi: 10.4172/0974-8369.1000249

20. Pennock BE, Schwan HP (1969) Further observations on the electrical properties of hemoglobin-bound water. J Phys Chem 73: 2600-2610.

21. Talary MS, Dewarrat $F$, Huber D, Caduff $A(2007)$ In vivo life sign application of dielectric spectroscopy and non-invasive glucose monitoring. J Non-Crys Solids 353: 4515-4517.

22. Pliquett F, Pliquett $U$ (1992) Tissue impedance, measured by pulse deformation. In: Lahtinen T (ed) The 8th International Conference on Electrical Bio-impedance, University of Kuopio, Finland.

23. Loft SM, Conway J, Brown BH (1992) Bioimpedance and cancer therapy. In: Lahtinen T (ed) The 8th International Conference on Electrical Bio-impedance, University of Kuopio, Finland.

24. Pethig R (1984) Dielectric properties of biological materials: biophysical and medical application. IEEE Transactions on Electrical Insulation E1-19: 453-474.

25. Vincze G, Szasz N, Szasz A (2005) On the thermal noise limit of cellular membranes. Bioelectromagnetics 26: 28-35

26. Gao RC, Zhang XD, Sun YH, Kamimura Y, Mogilner A, et al. (2011) Different roles of membrane potentials in electrotaxis and chemotaxis of dictyostelium cells. Eukaryot Cell 10: 1251-1256

27. Kotnik T, Miklavcic D (2000) Theoretical evaluation of the distributed power dissipation in biological cells exposed to electric fields. Bioelectromagnetics 21: $385-394$

28. Gowrishankar TR, Weaver JC (2003) An approach to electrical modeling of single and multiple cells. Proc Natl Acad Sci USA 100: 3203-3208.

29. Karnovsky MJ, Kleinfeld AM, Hoover RL, Klausner RD (1982) The concept of lipid domains in membranes. J Cell Biol 94: 1-6.

30. Rajendran L, Simons K (2005) Lipid rafts and membrane dynamics. J Cell Sc 118: 1099-1102.

31. Hille B (1992) Ionic channels of excitable membranes. Sunderland, Massachusetts: Sinauer.

32. Adair RK (2003) Biophysical limits on athermal effects of RF and microwave radiation. Bioelectromagnetics 24: 39-48.

33. Horváth I, Multhoff G, Sonnleitner A, Vígh L (2008) Membrane-associated stress proteins: more than simply chaperones. Biochim Biophys Acta 1778: 1653-1664.

34. Santoni G, Farfariello V, Amantini C (2011) TRPV channels in tumor growth and progression. Adv Exp Med Biol 704: 947-967.

35. Santoni G, Farfariello V (2011) TRP channels and cancer: new targets for diagnosis and chemotherapy. Endocr Metab Immune Disord Drug Targets 11: 54-67.

36. Lazzeri M, Vannucchi MG, Spinelli M, Bizzoco E, Beneforti P,et al. (2005) Transient receptor potential vanilloid type 1 (TRPV1) expression changes from normal urothelium to transitional cell carcinoma of human bladder. Eur Urol 48: 691-698.

37. Kalogris C, Caprodossi S, Amantini C, Lambertucci F, Nabissi M, et al. (2010) Expression of transient receptor potential vanilloid-1 (TRPV1) in urothelia cancers of human bladder: relation to clinicopathological and molecular parameters. Histopathology 57: 744-752.

38. Li S, Bode AM, Zhu F, Liu K, Zhang J, et al. (2011) TRPV1-antagonist AMG9810 promotes mouse skin tumorigenesis through EGFR/Akt signaling. Carcinogenesis 32: 779-785.

39. White JP, Urban L, Nagy I (2011) TRPV1 function in health and disease. Curr Pharm Biotechnol 12: 130-144.

40. Nilius B, Talavera K, Owsianik G, Prenen J, Droogmans G, et al. (2005) Gating of TRP channels: a voltage connection? J Physiol 567: 35-44.

41. Chung MK, Güler AD, Caterina MJ (2005) Biphasic currents evoked by chemical or thermal activation of the heat-gated ion channel, TRPV3. J Biol Chem 280: 15928-15941.

42. Brauchi S, Orio P, Latorre R (2004) Clues to understanding cold sensation: thermodynamics and electrophysiological analysis of the cold receptor TRPM8. Proc Natl Acad Sci USA 101: 15494-15499.

43. Voets T, Droogmans G, Wissenbach U, Janssens A, Flockerzi V, et al. (2004) The principle of temperature-dependent gating in cold- and heat-sensitive TRP channels. Nature 430: 748-754.
44. Pinton P, Giorgi C, Siviero R, Zecchini E, Rizzuto R (2008) Calcium and apoptosis: ER-mitochondria $\mathrm{Ca} 2+$ transfer in the control of apoptosis. Oncogene 27: 6407-6418.

45. Mimura T, Tazawa T (1983) Effect of intracellular Ca2+ on membrane potential and membrane resistance in tonoplast-free cells of Nitellopsis obtuse; Protoplasma 118: 49-55

46. Mason MJ, Hussain JF, Mahaut-Smith MP (2000) A novel role for membrane potential in the modulation of intracellular $\mathrm{Ca} 2+$ oscillations in rat megakaryocytes. J Physiol 524 Pt 2: 437-446.

47. Levin M (2007) Large-scale biophysics: ion flows and regeneration. Trends Cell Biol 17: 261-270.

48. Shapovalov G, Lehen'kyi V, Skryma R, Prevarskaya N (2011) TRP channels in cell survival and cell death in normal and transformed cells. Cell Calcium 50: 295-302.

49. Hanley PJ, Musset B, Renigunta V, Limberg SH, Dalpke AH, et al. (2004) Extracellular ATP induces oscillations of intracellular $\mathrm{Ca} 2+$ and membrane potential and promotes transcription of IL-6 in macrophages. Proc Natl Acad Sci USA 101: 9479-9484.

50. Orrenius S, Zhivotovsky B, Nicotera P (2003) Regulation of cell death: the calcium-apoptosis link. Nat Rev Mol Cell Biol 4: 552-565

51. Singer SJ, Nicolson GL (1972) The fluid mosaic model of the structure of cell membranes. Science 175: 720-731.

52. Saffman PG, Delbrück M (1975) Brownian motion in biological membranes. Proc Natl Acad Sci USA 72: 3111-3113.

53. Lund M, Jönsson B, Woodward CE (2007) Implications of a high dielectric constant in proteins. J Chem Phys 126: 225103.

54. Goswami C, Hucho T (2008) Submembraneous microtubule cytoskeleton: biochemical and functional interplay of TRP channels with the cytoskeleton. FEBS J 275: 4684-4699

55. Meggyesházi N, Andocs G, Balogh L, Balla P, Kiszner G, et al. (2014) DNA fragmentation and caspase-independent programmed cell death by modulated electrohyperthermia. Strahlenther Onkol 190: 815-822.

56. Andocs G, Renner H, Balogh L, Fonyad L, Jakab C, et al. (2009) Strong synergy of heat and modulated electromagnetic field in tumor cell killing. Strahlenthe Onkol 185: 120-126.

57. Becker R (1949) Theory der Elektrizitat I. Teubner, Stuttgart.

58. von Hippel A (1954) Dielectrics and waves, John Wiley and Sons Inc.

59. Barett TW, Pohl HA (1987) Energy Transfer Dynamics. Springer-Verlag, Berlin

60. Grodzinski AJ (1998) Fields, forces and flows in biological tissues and membranes. Massachusetts Institute of Technology.

61. Kotnik T1, Miklavcic D (2000) Second-order model of membrane electric field induced by alternating external electric fields. IEEE Trans Biomed Eng 47 1074-1081.

62. Garner AL (2013) Cell membrane thermal gradients induced by electromagnetic fields. Journal of Applied Physics 113: 214701-214711.

63. Smythe WR (1939) Static and dynamic electricity. McGraw-Hill, New York and London.

64. Lee RC, Aarsvold JN, Chen W, Astumian RD, Capelli-Schellpfeffer M, et al (1995) Biophysical mechanisms of cell membrane damage in electrical shock. Semin Neurol 15: 367-374.

65. Kirson ED, Gurvich Z, Schneiderman R, Dekel E, Itzhaki A, et al. (2004) Disruption of cancer cell replication by alternating electric fields. Cancer Res 64: 3288-3295.

66. http://www.novocure.com/files/files/2013-11-18\%20SNO\%20Abstracts.pdf (accessed Jun. 2014)

67. Chang CH, Tsong TY (2004) Stochastic resonance in a biological motor under complex fluctuations. Phys Rev E Stat Nonlin Soft Matter Phys 69: 021914

68. ALSUntangled Group (2014) ALSUntangled no. 23: the Rife machine and retroviruses. Amyotroph Lateral Scler Frontotemporal Degener 15: 157-159.

69. Rosenow EC (1932) Observations with the Rife Microscope of Filter-Passing Forms of Microorganisms. Science 76: 192-193. 
Citation: Vincze Gy, Szigeti Gy, Andócs G and Szász A. (2015) Nanoheating without Artificial Nanoparticles. Biol Med (Aligarh) 7: 249. doi: 10.4172/0974-8369.1000249

Page 9 of 9

70. Zimmerman JW, Pennison MJ, Brezovich I, Yi N, Yang CT, et al. (2012) Cancer cell proliferation is inhibited by specific modulation frequencies. $\mathrm{Br} \mathrm{J}$ Cancer 106: $307-313$

71. Loewenstein WR (1999) The touchstone of life, Molecular information, cell communication and the foundations of the life. Oxford University Press, Oxford, New York, NY

72. Davidov AS (1982) Biology and Quantum mechanics, Pergamon Press, Oxford

73. Del Giudice E, Doglia S, Milani M (1983) Self-focusing and ponderomotive forces of coherent electric waves: a mechanism of cytoskeleton formation and dynamics, In: Frolich H, Kremer F (eds). Springer Berlin, Heidelberg.

74. Szasz A (1991) An electronically driven instability: the living state (Does the room-temperature superconductivity exist?) Physiol Chem Phys 23: 43-50.

75. Szasz A, van Noort D, Scheller A, Douwes F (1994) Water states in living systems. I. Structural aspects. Physiol Chem Phys Med NMR 26: 299-322.

76. Frolich H (1988) Biological coherence and response to external stimuli. Springer Verlag, Berlin Heidelberg.

77. Voss RF (1989) Random fractals: self-affinity in noise, music, mountains and clouds. Physica D 38: 362-371.

78. Adey RW (1992) Collective properties of cell membranes. In Interaction Mechanisms of Low-level Electromagnetic Fields in Living Systems, Norden B, Ramel C (eds) Oxford University Press, Oxford; New York, NY.

79. Adey WR (1993) Biological effects of electromagnetic fields. J Cell Biochem 51: $410-416$
80. Foster KR, Repacholi MH (2004) Biological effects of radiofrequency fields: does modulation matter? Radiat Res 162: 219-225.

81. Blackman CF (2012) Treating cancer with amplitude-modulated electromagnetic fields: a potential paradigm shift, again? $\mathrm{Br} \mathrm{J}$ Cancer 106: 241-242.

82. Barbault A, Costa FP, Bottger B, Munden RF, Bomholt F, et al. (2009)Amplitudemodulated electromagnetic fields for the treatment of cancer: Discovery of tumour-specific frequencies and assessment of a novel therapeutic approach. J Exp Clin Cancer Res 28: 51-61.

83. Blackman CF, Elder JA, Weil CM, Benane SG, Eichinger DC, et al. (1979) Induction of calcium ion efflux from brain tissue by radiofrequency radiation effects of modulation-frequency and field strength. Radio Sci 14: 93-98.

84. Blackman CF (2007) Evidence for Disruption by the modulating signal; Biolnitiative Working Group, USA

85. Costa FP, de Oliveira AC, Meirelles R, Machado MCC, Zanesco T, et al. (2011) Treatment of advanced hepatocellular carcinoma with very low levels of amplitude-modulated electromagnetic fields. $\mathrm{Br} \mathrm{J}$ Cancer 105: 640-648.

86. Rakovic D, Djordjevic D (2012) Wear amplitude modulated RF EM fields for cancer treatment. Med Rev 4: 089-092.

87. Szasz O, Andocs G, Meggyeshazi N (2013) Modulation effect in oncothermia, Conf Papers Med 1-5.

88. Wust P (2005) Thermoregulation in humans - Experiences from thermotherapy; Conference in Stuttgart,

89. Erdmann B, Lang J, Seebass M (1998) Optimization of temperature distributions for regional hyperthermia based on a nonlinear heat transfer model. Ann NY Acad Sci 858: 36-46.
Citation: Vincze Gy, Szigeti Gy, Andócs G and Szász A. (2015) Nanoheating without Artificial Nanoparticles. Biol Med (Aligarh) 7: 249. doi: 10.4172/0974 8369.1000249
Submit your next manuscript and get advantages of OMICS Group submissions

Unique features:

- User friendly/feasible website-translation of your paper to 50 world's leading languages

Audio Version of published paper

Digital articles to share and explore

Special features:

400 Open Access Journals

30,000 editorial team

21 days rapid review process

Quality and quick editorial, review and publication processing

- Indexing at PubMed (partial), Scopus, EBSCO, Index Copernicus and Google Scholar etc

- Sharing Option: Social Networking Enabled

- Authors, Reviewers and Editors rewarded with online Scientific Credits

- Better discount for your subsequent articles

Submit your manuscript at: http://www.omicsonline.org/submission 